\title{
ARCHAEOCYATH PALAEOECOLOGY
}

HART, S. Fraser, Dept. of Earth Sciences, Downing Street, Cambridge, CB2 3EQ. U.K.

A well preserved archaeocyath fauna occurs in the Forteau Formation in Southern Labrador, Canada. Following on from the confirmation that archaeocyatha are aspiculate calcified sponges, detailed ecological work is now being undertaken on this fauna, a representative of the first reefal ecosystem in the fossil record.

One species, Metaldetes profundus, shows considerable variability in growth form, from open bowl-shaped forms in lagoonal settings, to a branching morphology in biohermal habitats. This species also appears to colonise a variety of substrate types and for this purpose often uses exothecal structures and holdfasts. M.profundus is also the dominant species numerically, comprising $80 \%$ of the fauna, except at the top of the bioherm horizon, where Archaeocyathus atlanticus becomes dominant. In contrast to previous studies' findings, bowl-shaped Metaldetes at the top of the bioherm horizon occupy the basal region of the bioherms, not the upper areas and provide a surface on which the bioherms can develop.

The unique form of Retilamina amourensis endows it with the ability to stabilise substrates so facilitating the colonization of a substrate. It is more common at the base of bioherms, providing a surface on which other archaeocyaths can settle. The calcimicrobes Renalcis and Epiphyton also appear to have played a major role in the initiation of the bioherms, occurring as $3-5 \mathrm{~cm}$ thick layers on erosion surfaces, within which small, juvenile, upright $M$.profundus sticks, $<1 \mathrm{~cm}$ in diameter, are found, surrounded and supported by the dense calcimicrobe aggregate.

Digital 3-D analysis is being used to document the behaviour of the archaeocyaths, together with vertical and lateral zonation within the bioherms, especially with regard to the timing of calcimicrobe encrustation. Volumetric abundances of the archaeocyaths are also being calculated.

There are small faunal composition changes over the area: Archaeosycon billingsi, a solitary stick-like form is more abundant in the west than in the east and Archaeocyathus atlanticus, another stick-like form occurs in dense clusters in lagoonal environments, elsewhere being solitary. 